\title{
O LUGAR DA PRISÃo NA NOVA ADMINISTRAÇÃO DA POBREZA*
}

\author{
LOÏC WACQUANT \\ tradução: Paula Miraglia e Hélio de Mello Filho
}

\section{RESUMO}

A sociedade norte-americana é cinco vezes mais punitiva hoje do que há 25 anos. O acionamento da luta contra o crime serviu tão-somente como pretexto e trampolim para uma reformulação do perímetro e das funções do Estado, que resultou no enxugamento do seu componente de welfare. $\mathrm{O}$ complexo penitenciário ganhou um lugar central como instrumento para a administração da pobreza, nas encruzilhadas do mercado de trabalho desqualificado, no colapso do gueto urbano e nos serviços de bem-estar social "reformados" de modo a reforçar a disciplina do trabalho assalariado dessocializado.

PALAVRAS-CHAVE:prisão; administração da pobreza; welfare; workfare.

\section{ABSTRACT}

The irresistible rise of the penal state in the United States manifests the implementation of a policy of criminalization of poverty that is the indispensable complement to the imposition of precarious and underpaid wage labor as civic obligation for those trapped at the bottom of the class and caste structure. The prison has thus regained a central place in the panoply of instruments for the government of poverty, at the crossroads of the deskilled labor market, the collapsing urban ghetto, and social-welfare services "reformed" with a view to buttressing the discipline of desocialized wage work.

KEYWORDS: prison; workfare; ghetto; poverty; United States;

neoliberalism.

[*] Aser publicado em Marie-Louie Frampton, Ián Haney Lopez e Jonathan Simon (eds.), After the war on crime (New York: New York University Press, 2008). Este artigo reformula argumentos do livro Prisões da miséria, publicado no Brasil pela editora Jorge Zahar em 2001.
[1] Bureau of Justice Statistics.Sourceboook of Criminal Justice Statistics 2000. Washington:Government Printing Office, 2001, p. 528.
Apreender a mudança das funções do estado penal na era pós-fordista e pós-keynesiana exige uma dupla ruptura. Primeiro, deve-se romper o paradigma do "crime e castigo", materializado pela criminologia e o direito penal, que nos mantém confinados à perspectiva estreita da imposição do cumprimento da lei, incapaz de considerar o grau cada vez maior de punições aplicadas pelas autoridades, que ignoram na mesma proporção as finalidades extrapenais da prisão. Basta uma única estatística para fazer sobressair a falta de conexão flagrante e crescente entre crime e encarceramento nos Estados Unidos:em 1975, o país prendia 21 criminosos para cada 1.000 crimes graves (homicídio, estupro, agressão, roubo, assalto e furto de carros); em 1999, este número havia chegado a 106ํ. Se considerarmos o crime como uma constante, a sociedade norte-americana é cinco vezes mais punitiva hoje do que era há um quarto de século. Porém,é preciso afastar o conto oposicionista do "complexo industrial prisional", defendido por ativistas, jornalistas e acadêmicos mobilizados contra a escalada 
penal, que de formas variadas atribuem equivocadamente a explosão do encarceramento dos Estados Unidos à reestruturação global do capitalismo, que intensificou o racismo, eà corrida frenética em busca do lucro por meio da construção de penitenciárias e da superexploração do trabalho de detentos.

Quando paramos para pensar sobre o assunto, também percebemos que a expressão "guerra contra o crime" é inapropriada sob três aspectos, retóricos tanto quanto materiais. Em primeiro lugar, guerras são empreendidas por militares contra inimigos externos da nação, enquanto o combate ao crime, independentemente do quão duro seja, envolve órgãos civis que lidam com cidadãos e detentos protegidos por uma série de direitos e que, ao invés de serem expulsos ou aniquilados, são reintroduzidos na sociedade após um período em custódia penal ${ }^{2}$. Segundo, a chamada guerra declarada por autoridades federais e locais nunca foi empreendida contra o "crime" em geral. O alvo na verdade eram determinadas categorias de ilegalidades cometidas em um setor bem definido dos espaços físico e social: basicamente crimes de rua cometidos em bairros de classes desfavorecidas e segregadas das metrópoles norte-americanas. Terceiro, e mais importante: o acionamento da luta contra o crime serviu tão-somente como pretexto e trampolim para uma reformulação do perímetro e das funções do Estado, que resultou no enxugamento (downsizing) do seu componente de welfare ${ }^{3}$ e no inchaço (upsizing) dos seus setores policiais, jurídicos e correcionais.

\section{O NEXO INSTITUCIONAL TRIÁDICO DA PRISÃO}

Entre 1975 e 2000 , a população carcerária dos Estados Unidos cresceu em termos exponenciais, passando de 380 mil a 2 milhões de detentos, enquanto o número de beneficiários do welfare caiu vertiginosamente de 11 para menos de 5 milhões. Ao quadruplicar o número de detentos entre 1980 e 2000 e submeter algo em torno de 6,5 milhões de pessoas à supervisão da justiça penal (incluindo os indivíduos em liberdade condicional e sursis), os Estados Unidos aumentaram os orçamentos conjuntos das administrações penitenciárias federal, estadual e municipal em US $\$ 50$ bilhões, e acrescentaram 500 mil novos funcionários, tornando as cadeias e penitenciárias do país no terceiro maior empregador em 1998, atrás apenas da Manpower Incorporated e da Wal-Mart. A cada ano, desde 1985, os gastos nacionais com o encarceramento superaram os fundos alocados para o Food Stamps e o AFDC: em 1995, às vésperas da "reforma do welfare", os Estados Unidos gastavam US $\$ 46$ bilhões na operação das casas de detenção contra menos de US $\$ 20$ bilhões como AFDC4. Ainda assim, em razão de as administrações públicas não terem sido capazes de se
[2] A toda a conversa de "trancafiálos e jogar a chave fora", opõe-se o fato de que $95 \%$ de todos os presos convictos encarcerados em prisões federais e estaduais acabam sendo soltos. Os detentos sentenciados à prisão perpétua ou à morte representam 3.500 indivíduos, de toda a população carcerária (Donziger, Marc R. The real war on crime. New York: Harper Perennial, 1996, p.126).

[3] O termo welfare foi deixado propositalmente em inglês não apenas por ser amplamente adotado assim, mas também, e sobretudo, porque é utilizado neste artigo em contraposição a workfare, que só poderia ser traduzido por uma expressão explicativa, o que poluiria o texto pela quantidade de vezes em que aparece [N. do T.].

[4] Gifford, Sidra Lea.Justice expenditures and employment in the United States, 1999. Washington: Bureau of Justice Statistics, 2002, p. 8; Committee on Ways and Means. 1996 Green Book. Washington: Government Printing Office, 1997, p. 921. 
[5] Rothman, David.The discovery of the asylum: social order and disorder in the New Republic (Boston: Little Brown, 1971), pp. 254-255. expandir o suficiente para conter a onda em crescimento contínuo de presos convictos, a explosão carcerária levou ao renascimento do encarceramento privado. Em apenas uma década, operadores com fins lucrativos dominaram $7 \%$ do "mercado", oferecendo 120 mil vagas adicionais em 1998, o que equivale à população carcerária da França, Itália e Espanha juntas.

No entanto, é sobretudo a lógica intrínseca desta virada do registro social para o penal, mais do que as particularidades sobre dados e tendências estatísticas, que merece ser assimilada. Longe de contradizer o projeto neoliberal de desregulamentação e degradação do setor público, a ascensão irrefreável do estado penal norte-americano constitui, por assim dizer, o seu negativo (ou seja, é a um só tempo a revelação e a manifestação do seu reverso), uma vez que evidencia a implementação de uma política de criminalização da pobreza, que éo complemento indispensável à imposição de ofertas de trabalho precárias e mal remuneradas na forma de obrigações cívicas para aqueles que estão cativos na base da estrutura de classes e castas, bem como a reimplantação concomitante de programas de welfare reformulados com uma face mais restritiva e punitiva. Na época da sua institucionalização, nos Estados Unidos de meados do século XIX, "o encarceramento era, acima de tudo, um método que al mejava o controle de populações divergentes e dependentes" pessoas pobres e imigrantes europeus recém-chegados ao Novo Mundo. Hoje em dia, o aparato carcerário norte-americano desempenha um papel análogo no que diz respeito a esses grupos, transformados em supérfluos ou discrepantes pela dupla reestruturação da relação entre o trabalho assalariado e a caridade do Estado: as porções decadentes da classe trabalhadora e dos negros pobres ficaram presos aos centros das cidades, uma dia industrializados, agora degradados. Dessa forma, ele pôde ganhar um lugar central na panóplia de instrumentos para a administração da pobreza, nas encruzilhadas do mercado de trabalho desqualificado, no colapso do gueto urbano e nos serviços de bem-estar social "reformados" de modo a reforçar a disciplina do trabalho assalariado dessocializado.

\section{A PRISÃO E O MERCADO dE TRABALHO dESQUALIFICAdO}

Em primeiro lugar, o sistema penal contribui diretamente para a regulamentação dos segmentos mais baixos do mercado de trabalho - e o faz de um modo mais coercitivo e significativo do que a legislação trabalhista, os sistemas de seguridade social e outras políticas públicas, muitas das quais nem mesmo abrangem o trabalho não-regulamentado. Seus efeitos nesta linha de frente são tripartidos. Primeiro, a prevalência e a escalada impressionantes das sanções penais ajudam a disciplinar as 
parcelas reticentes da classe trabalhadora, aumentando o custo das estratégias de resistência ao trabalho assalariado dessocializado por intermédio de uma "saída" para a economia informal. Afrontados por uma polícia agressiva, tribunais severos e a possibilidade de sentenças de prisão estupidamente longas para crimes envolvendo drogas ilícitas e reincidência, muitos evitam entrar ou afastam-se do comércio ilegal de rua e submetem-se aos princípios do trabalho não-regulamentado. Para alguns dos recém-saídos de uma instituição carcerária, a intrincada malha da supervisão pós-correcional aumenta a pressão para a opção pela vida "do caminho certo" ancorada no trabalho, quando disponível ${ }^{6}$. Em um caso como no outro, o sistema de justiça penal atua em anuência com o workfare 7 , para forçar a entrada da sua clientela nos segmentos periféricos do mercado de trabalho.

Segundo, o aparato carcerário ajuda a "fluidificar" o setor de empregos mal remunerados e reduz de maneira artificial a taxa de desemprego, subtraindo à força milhões de indivíduos desqualificados da força de trabalho. Estima-se que o confinamento carcerário tenha diminuído o índice de desempregados nos Estados Unidos em dois pontos percentuais durante a década de 1990. Com efeito, segundo Bruce Western e Katherine Beckett, quando se contabilizou a diferença entre o nível de encarceramento das duas áreas, os Estados Unidos divulgaram uma taxa de desemprego mais alta do que a média para a União Européia durante dezoito dos vinte anos entre 1974 e 1994, contrariando a visão propalada pelos entusiastas do neoliberalismo e críticos da "euroesclerose" 8 . Ainda que seja verdade que nem todos os prisioneiros fariam parte da força de trabalho se estivessem em liberdade, a diferença de dois pontos percentuais não inclui o estímulo keynesiano proporcionado pela explosão dos gastos públicos e do emprego em instituições correcionais: o número de empregos nas cadeias e prisões municipais, estaduais e federais mais que dobrou nas últimas duas décadas, saltando de menos de $300 \mathrm{mil}$ em 1982, para mais de 716 mil em 1999, quando a folha de pagamento mensal excedia US $\$ 2,1$ bilhões 9 . O crescimento penal também impulsionou o emprego no setor privado de produtos e serviços carcerários, um setor com altas taxas de empregos precários e rotatividade, e que cresce paralelamente à privatização da punição (já que a fonte da "competitividade" das empresas correcionais são os salários incrivelmente baixos e os benefícios insuficientes concedidos ao seu quadro de empregados).

Western e Beckett argumentam que a hipertrofia carcerária é um mecanismo tardio, bipartido e com efeitos contraditórios: a um só tempo doura o cenário trabalhista de curto prazo, amputando o suprimento de trabalho na base da hierarquia ocupacional, e agrava-o a longo prazo, inviabilizando em menor ou maior intensidade milhões
[6] Nelson, Marta, Dees, Perry e Allen, Charlotte. The first month out: post-incarceration experiences in New York City. New York: Vera Institute, 1999.

[7] Termo usado em contraposição ao welfare, e que implica o condicionamento do trabalho para a concessão da assistência pública [N.do T.].

[8] Western, Bruce e Beckett, Katherine. "How unregulated is the U.S. labor market? The penal system as a labor market institution". American Journal of Sociology, vol. 104, $\mathrm{n}^{2} 4$, 1999, pp.1030-1060.

[9] Isso dá aos Estados Unidos 24 empregados penitenciários para cada 10 mil residentes em "equivalentes de tempo integral" contra 4 por 10 mil na França (efetivo de 24.220), 5 na Espanha (22.035) e 8 na Inglaterra e no País de Gales (41.065) [de acordo com dados de Tournier, Pierre V. Space I (Statistique Pénale Annuelle du Conseil del'Europe): Enquête 2000 surlespopulations pénitentiaires, version définitive. Strasbourg: Conseil de Coopération Pénologique, PC-CP, 2001, p. 47]. 
[1o] Western e Beckett,op.cit.,p.1031.

[11] Peck,Jamie e Theodore, Nikolas. "The business of contingent work: growth and restructuring in Chicago's temporary employment industry". Work, Employment \& Society, vol. 12, n' 4,1998,pp. 655-674; Barker, Kathleen e Kristensen, Kathleen (eds.). Contingent work: American employment relations in transition. Ithaca: Cornell University Press, 1998.
[12] Para uma elaboração histórica $e$ conceitual compacta sobre o acoplamento entre (hiper)gueto e prisão após odeclínio gradual do Movimento dos Direitos Civis, ver L. Wacquant. "The new 'peculiar institution': On the prison as surrogate ghetto" (Theoretical Criminology, vol. 4, n⿳203, 2000, pp. 377-389); para uma exposição completa e detalhada sobre a extensão do modelo teórico para a Europa Ocidentaleo Brasil,veridem.Deadlysymbiosis: race and the rise of the penal state (Cambridge: Polity Press, 2008). de pessoas para o trabalho. Na visão desses autores, "o encarceramento reduziu a taxa de desemprego dos Estados Unidos, mas [...] sustentar índices baixos de desemprego no futuro vai depender da expansão do sistema penal"1o. Porém, esse argumento ignora um terceiro impacto do ultra-encarceramento sobre o mercado de trabalho, queé o de facilitar o crescimento da economia informal e de empregos abaixo da linha de pobreza, e o faz gerando continuamente um grande volume de trabalhadores marginais que podem ser explorados sem quaisquer escrúpulos. Ex-detentos dificilmente podem exigir algo melhor que um emprego degradante e degradado em razão das trajetórias interrompidas, dos laços sociais esgarçados, do status jurídico ignominioso e do amplo leque de restrições legais e obrigações civis implicadas. $O$ meio milhão de condenados que escoam das prisões americanas todos os anos fornece a força de trabalho vulnerável apropriada para suprir a demanda de empregos temporários, o setor do mercado de trabalho que mais cresceu nos Estados Unidas ao longo das duas últimas décadas (e que responde por um quinto de todos os novos empregos criados desde 1984) ${ }^{11}$. O encarceramento extremo, portanto, alimenta o emprego contingente, que é a linha de frente da flexibilização do trabalho assalariado nas camadas mais baixas da distribuição de empregos. Além disso, a proliferação de penitenciárias nos Estados Unidos (seu número triplicou em trinta anos, e já ultrapassa 4.800) contribui diretamente para o crescimento ea disseminação do tráfico ilícito (drogas, prostituição, produtos roubados), que são o motor do capitalismo de pilhagem das ruas.

\section{A PRISÃO E A IMPLOSÃO dO GUETO}

A representação maciçamente predominante e crescente de afroamericanos em qualquer nível do aparato penal tinge a segunda função assumida pelo sistema carcerário da nova administração da pobreza na América de uma cor desagradável: compensare complementar afalência do gue to como mecanismo de confinamento de uma população considerada divergente, desonesta e perigosa, bem como supérflua no plano econômico (imigrantes mexicanos e asiáticos são trabalhadores mais dóceis) e no plano político (negros pobres raramente votame, de qualquer forma, o centro gravitacional eleitoral mudou das regiões centrais urbanas decadentes para os prósperos subúrbios brancos) ${ }^{12}$.

Desse ângulo, o encarceramento é apenas a manifestação paroxística da lógica da exclusão etnorracial da qual o gueto tem sido instrumento e produto desde a sua origem histórica. Durante o meio século de domínio da economia industrial fordista(1915-1965) - para aqual os negros contribuíram com uma quantidade indispensável de trabalho não-qualificado, desde a Primeira Guerra Mundial, que pôs em 
marcha a "Grande Migração" dos estados segregacionistas do Sul para as metrópoles de trabalhadores do Norte, até a Revolução dos Direitos Civis, que finalmente lhes deu acesso às urnas (cem anos depois da abolição da escravidão) - , o gueto desempenhou o papel de "prisão social", garantindo, assim, o ostracismo social sistemático de afroamericanos e ao mesmo tempo permitindo a exploração da sua força de trabalho na cidade. Após a crise de debilitação do gueto, simbolizada pela grande onda de revoltas urbanas que varreram o país em meados da década de 1960, a prisão preencheu o espaço que se abriu, servindo como um "gueto" substituto para armazenar as parcelas do (sub)proletariado negro que têm sido marginalizadas pela transição à economia de serviços duplos e às políticas estatais de retração do welfare e de retirada das cidades ${ }^{13}$.

Logo, ambas as instituições acoplaram-se e complementaram-se, pois cada uma opera à sua própria maneira para reforçar a separação (o significado etimológico de segregare) de uma categoria indesejada, percebida como uma ameaça dupla para a metrópole, indissociavelmente moral e física. E essa simbiose estrutural e funcional entre gueto e prisão encontra uma expressão cultural surpreendente nas letras musicais e no estilo de vida desdenhoso dos músicos de gangsta rap, exemplificado pelo destino trágico do cantor e compositor Tupac Shakur. Nascido na prisão, filho de um pai ausente (sua mãe, Afeni Sahkur, fazia parte dos Panteras Negras), o apóstolo da thuglife, herói para uma multidão de jovens dos guetos (e legiões de adolescentes brancos dos subúrbios), morreu em 1996, em Las Vegas, crivado de balas em um carro, após cair numa emboscada armada por membros da gangue rival.Antes disso, foi acusado de atirar contra policiais e cumpriu pena de oito meses por agressão sexual. ${ }^{14}$

\section{A PRISÃO E O WELFARE TRANSFORMADO EM WORKFARE}

Assim como no seu nascimento, a prisão como instituição está diretamente vinculada ao conjunto de organizações e programas encarregados de prestar "assistência" às populações desfavorecidas, e alinhada à crescente interpenetração organizacional e ideológica entre os setores penal e social do estado pós-keynesiano. Por um lado, a lógica panóptica e punitiva própria ao campo penal tende a contaminar e em seguida redefinir os objetivos e mecanismos de prestação de assistência pública ${ }^{15}$. Desse modo, além de substituir o direito de crianças desfavorecidas à assistência estatal pela obrigação de seus pais trabalharem após dois anos, a "reforma do welfare", endossada por Clinton em 1996, sujeita os beneficiários da assistência pública às práticas intrusivas do registro vitalício de informações e controle rígido, bem como estabeleceum monitoramento rigoroso de suas condutas - no que diz respeito
[13] Kerner Commission. The Kerner report: The 1968 report of the national advisory commission on civil disorders. New York: Pantheon, 1969/1989; Harris, Fred R. e Curtis, Lynn (eds.). Locked in the poorhouse: Cities, race, and poverty in the United States. Lanham: Rowman \& Littlefield, 1998; Wacquant, L.Urban outcasts: A comparative sociology of advanced marginality. Cambridge: Polity Press 2007.

[14] White,Armond. Rebel for the hell of it: Life of Tupac Shakur. London: Quartet Books, 1997/2002.

[15] Katz, Michael B.In the shadow of the poorhouse: A social history of welfare in America. New York: Basic Books, 1996, pp. 300-334; Handler, Joel e Hasenfeld, Yeheskel. We the poor people: Work, poverty, and welfare. New Haven:Yale University Press, 1997. 
[16] Fuller, Torrey E. "Jails and prisons: America's new mental hospitals". America Journal of Public Health vol. $85, \mathrm{n}^{\mathrm{Q}} 12,1995$, pp. 1611-1613.
[17] Lilly, J. Robert e Knepper, Paul. "The corrections-commercial complex". Crime and Delinquency, vol.39, $\mathrm{n}^{\mathrm{Q}}$ 2, 1993, pp. 150-166; Schlosser, Eric. "The prison-industrial complex". The Atlantic Monthly, vol. 282, dez. 1998, pp. 51-77; Goldberg, Eve e Evans, Linda. The prison industrial complex and the global economy. Boston: Kersplebedeb, 1998. Uma coleção valiosa de escritos, demandas e informações de ativistas sobre os tópicos está reunida no site <www.prisonsucks.com>, administrado pela Prison Policy Initiative (sediada em Northampton, Massachusetts). à educação, emprego, consumo de drogas e sexualidade - por força do qual podem ser acionadas sanções administrativas e criminais. Um exemplo: desde 1998, na região central de Michigan, os beneficiários de programas de assistência social devem se submeter a testes de uso de drogas periódicos, da mesma forma que os condenados em liberdade condicional ou sursis. Esses testes são realizados pelo Departamento Penitenciário Estatal em beneficiários e presos em liberdade condicional, todos juntos nas mesmas instalações. Poroutrolado, as instalações correcionais devem, nolensvolens, em condições de penúria e emergência permanentes, enfrentar as adversidades médicas e sociais que a sua "clientela" não conseguiu resolver do lado de fora: nas principais cidades do país, o abrigo para sem-teto de maior capacidade e as mais amplas instalações para doentes mentais prontamente acessíveis ao subproletariado é a prisão municipal ${ }^{16}$. E a mesma população oscila de um pólo ao outro desse continuum institucional, percorrendo uma trajetória quase fechada, que encerra sua marginalidade socioeconômica e intensifica seu senso de indignação.

Finalmente, as limitações orçamentárias e a moda política de "menos governo" convergiram para intensificar as tendências da reificação do welfare assim como as do encarceramento. Diversas jurisdições, como o Texas e o Tennessee, consignam uma parte considerável dos seus condenados a estabelecimentos privados e subcontratam firmas especializadas para a administração dos beneficiários da assistência pública, pois o estado não tem capacidade administrativa para implementar sua nova política de combate à pobreza. Essa é uma maneira de tornar pessoas pobres e prisioneiros (cuja grande maioria era pobre em liberdade e voltará a ser pobre quando libertada) "lucrativos", em termos ideológicos e econômicos. O que nós estamos testemunhando aqui é a gênese, não de um "complexo industrial prisional", como é sugerido por alguns criminólogos, acompanhados por um coro de jornalistas e ativistas dos movimentos pela justiça, mobilizados contra o crescimento do Estado Penal ${ }^{17}$, mas de uma forma organizacional verdadeiramente nova, um continuum carcerário-assistencial em parte explorado para fins lucrativos, que é a linha de frente do Estado liberal-paternalista nascente. Sua missão é vigiar e subjugar,e se necessário reprimir e neutralizar, as populações refratárias à nova ordem econômica que segue uma divisão do trabalho por sexo, com o seu componente penal voltando-se sobretudo aos homens eo componente assistencial exercendo sua tutela sobre as mulheres e crianças (desses mesmos homens). Ao manter a tradição política americana estabelecida durante a era colonial, esse corpo institucional formadoe in statu nascendi é caracterizado, por um lado, pela interpenetração entranhada entre os setores público e privado e, por outro, pela fusão das funções de estigmatização, reparação moral e repressão do Estado. 
Os acadêmicos, ativistas e cidadãos comuns preocupados, ou consternados, com o crescimento desgovernado do sistema penal norte-americano não foram capazes de detectar o ancoradouro institucional triádico da prisão por estarem obnubilados pelo vínculo aparente entre encarceramento e lucro. Na década passada, o refrão da ascensão de um "complexo industrial prisional" que teria sucedido (ou suplementado) o "complexo industrial militar" da Guerra Fria em que os gigantes da indústria da defesa reestruturavam-se com o abastecimento de armas para o Pentágono e, assim, proporcionavam poder de vigilância e punição aos pobres; o medo do "inimigo vermelho" no exterior era substituído pelo temor do "inimigo negro" no interior; e os operadores privados tramavam em surdina com políticos e oficiais do sistema penitenciário para constituir um "subgoverno" dissimulado, que direcionava a expansão carcerária desmedida para a exploração de uma força de trabalho cativa de crescimento exponencial - foi o leitmotiv do discurso de oposição à prisão nos Estados Unidos $^{18}$. Baseada em uma visão conspiratória de história, essa tese é solapada por quatro lacunas importantes, que derrubam a sua significância analítica e arruínam a sua pertinência prática.

Em primeiro lugar, reduz a transformação dúplice, conjunta e interativa dos componentes penal e social do campo burocrático à simples "industrialização" do encarceramento. Porém, a escala mutável do confinamento nos Estados Unidos é apenas um elemento da redefinição mais ampla do perímetro e das modalidades da ação do Estado voltada para as "populações problemáticas", residentes das profundezas do espaço social e urbano. Essa escala e sua explicação estão indissociavelmente vinculadas à transição paradigmática do welfare para o workfare. Em contraposição, a possibilidade de vínculo do capitalismo e do racismo (os dois réus favoritos do conto ativista sobre a malignidade do governo) com a "globalização" é muito ambígua, sendo que nenhum desses dois imensos evagos "ismos" proporciona as condições necessárias e suficientes para esse experimento carcerário norte-americano inaudito e singular. Para começar, a inflação carcerária nos Estados Unidos foi disparada muito antes da aceleração da mobilidade de capitais entre as fronteiras, e, também, outros países mais avançados, cujas economias haviam passado por uma internacionalização semelhante, apresentaram um crescimento apenas modesto das populações carcerárias, alimentado pelo alongamento das sentenças, e não pelo aumento das admissões ${ }^{19}$. Ademais, embora a operação do sistema de justiça seja marcada pelo preconceito etnorracial, é difícil perceber como a discriminação poderia ter se intensificado desde os anos 1970, dada a ênfase cada vez maior às salvaguardas e devidos processos
[18] Por exemplo, Donziger, op. cit.; Rosenblatt, Elihu (ed.). Criminal injustice: confronting the prison crisis. Boston: South End Press, 1996; Davis, Angela e Gordon, A.F. “Globalism and the prison-industrial complex: An interview with Angela Davis". Race and Class, vol.4O, $\mathrm{n}^{\mathrm{os}} 2-3$, 1999, pp. 145-157; Braz, Rose e outros. "Overview: Critical resistance to the prison-industrial complex" (Introduction to a symposium on "The Prison-Industrial Complex'). Social Justice, vol. $27, \mathrm{n}^{\mathrm{Q}} 3,2000$, pp. 1-5.

[19] A variante internacional do argumento do "complexo industrial prisional" que afirma que o aprisionamento de "pessoas do sexo feminino de cor, imigrantes e indígenas" em todo o planeta se deve à colisão entre estados e corporações de encarceramento privadas (Sudbury, Julia. Global lockdown: Race, gender, and the prison-industrial complex. New York: Routledge, 2005) é ainda mais implausível que a sua versão masculina nacional. 
[20] Hacker, Jacob S. The divided Welfare State: The battle over public and private social benefits in the United States. New York: Cambridge University Press, 2002. legais instituída no despertar da revolução dos direitos civis, sem falar na presença crescente de policiais, juízes, vigias, carcereiros, oficiais de condicional negros em todos os níveis do aparato penal.

Em segundo lugar, o imaginário do "complexo industrial prisional" enquadra-se no papel de força motriz dos interesses pecuniários de empresas quevendem serviços ou produtos correcionais, ou supostamente mantêm trancafiadas vastas reservas de mão-de-obra. Sustenta que o motivo do lucro é crucial para o aparecimento da prisão em massa, quando, na verdade, esta vincula-se principal e primordialmente a uma lógica e a um projeto politicos, ou seja, à construção de um estado pós-keynesiano, "liberal paternalista", apto à instituição do trabalho assalariado dessocializado eà propagação de uma ética renovada de trabalho e de "responsabilidade individual" que a reforça. $\mathrm{O}$ lucro com prisões não é a causa principal, mas uma conseqüência secundária e incidental do desenvolvimento hipertrófico do aparato penal. O fato de interesses privados estarem sendo beneficiados pela expansão das funções governamentais decerto não é novo tampouco específico ao encarceramento: a distribuição de todos os bens públicos importantes nos Estados Unidos, desde a educação e a habitação até a segurança e a saúde, confere um papel amplo para o terceiro setor e o setor de serviços e comércio - em relação, por exemplo, ao fornecimento de assistência médica e social, a punição permanece surpreendentemente pública ${ }^{20}$. A privatização tampouco é necessária para o crescimento carcerário. Banir a prisão com fins lucrativos não impediu a Califórnia de se unir à corrida frenética pelo confinamento. Entre 1980 e 2000,0 "Golden State" testemunhou sua população de detentos saltar de 27 mil para 160 mil; seu orçamento para o sistema carcerário decuplicar de US $\$ 400$ milhões para US $\$ 4,2$ bilhões; e o quadro de funcionários de penitenciárias inchar, passando de 8.400 para 48 mil, tudo isso sem abrirsequer uma única prisão privada para adultos. Na realidade, se os operadores comerciais simplesmente desaparecessem da noite para o dia, os estados e municípios enfrentariam interrupções operacionais, e mais superlotações e obstáculos de curto prazo ao crescimento, mas a prevalência e a fisionomia social do encarceramento permaneceriam intactas.

Da mesma forma, a denúncia ritual da superexploração de detentos em condições que evocam uma escravidão penal não pode esconder o fato de que apenas uma parcela ínfima e estagnada da população carcerária dos Estados Unidos trabalha para empresas externas (bem menos que $1 \%$, de acordo com as contas mais generosas) e que nenhum setor econômico se apóia, nem mesmo marginalmente, em trabalhadores presos. Em relação a prisioneiros que trabalham arduamente atrás das grades para setores estatais ou federais (cerca de $8 \%$, segundo as estatísticas mais condescendentes), sua produção 
é insignificante e eles são "empregados" com prejuízo líquido para o governo, ainda que sua atividade seja maciçamente subsidiada e fortemente protegida ${ }^{21}$. A despeito de seu crescimento, todavia, diante dos números brutos nacionais fica difícil concordar com o argumento de Goldberg e Evans ${ }^{22}$, de que o "complexo industrial prisional está se tornando cada vez mais central para o crescimento da economia norte-americana": os US $\$ 57$ bilhões que os Estados Unidos gastaram com prisões municipais, estaduais e federais em 2001 não chegam nem à metade de $1 \%$ do PIB de $\mathrm{U} \$ 10.128$ bilhões daquele ano. Longe de ser "um componente essencial da economia norte-americana", as prisões permanecem insignificantes do ponto de vista da produção e servem não como um estímulo geral para os lucros corporativos, mas como um escoadouro de dinheiro dos cofres públicos e um desvio sem sentido do capital financeiro.

Em terceiro lugar, a visão ativista tem como premissa um paralelismo equivocado entre as funções de defesa nacional do Estado e administração penal, que deixa de perceber esta diferença fundamental: a política militar é altamente centralizada e coordenada no plano federal, enquanto o controle da criminalidade é amplamente descentralizado e disperso entre autoridades federais, uma centena de departamentos estaduais de justiça e prisões, e milhares de administrações estaduais municipais responsáveis pelas polícias, tribunais e cadeias. A expressão "sistema de justiça criminal" oculta uma rede frouxa de agências burocráticas providas de um livre-arbítrio abrangente e destituídas de uma filosofia ou política penal em comum. Ainda que um grupo governante míope tivesse, de algum modo, inventado um plano terrível para transformar o sistema carcerário em uma indústria lucrativa, usando os corpos dos pobres de pele negra como "matéria-prima", não haveria uma única base de apoio que pudesse ter sido utilizada para garantir a sua realização. A tese simplista de que o lucro capitalista impulsiona o crescimento carcerário deixa sem explicação os mecanismos específicos que deram origem à notável convergência das tendências correcionais entre diferentes jurisdições dos Estados Unidos e é apenas mais um elemento que se soma ao "composto misterioso" do ultra-encarceramento nacional, dada a falta de um "precursor político distintivo" 22 .

Finalmente, constrangida pela sua abordagem acusatória, a noção confusa de "complexo industrial prisional" não leva em consideração os efeitos abrangentes da introdução, ainda que de uma maneira limitada e pervertida, da lógica do welfare no interior do universo carcerário em si. As instituições correcionais foram profundamente transformadas ao longo das últimas três décadas, não apenas pelas mudanças na escala e composição da sua clientela, mas também pelo movimento dos direitos dos presos, a racionalização e a profissionalização do con-
[21] No exercício fiscal de 2001, o UNICOR, o programa de Indústrias Prisionais Federais, empregou 22.600 detentos para a produção de uma variedade de mercadorias (uniformes de polícia, capacetes de kevlar, jogos de cama e cortinas, móveis de escritório, serviços de lavanderia, encadernação, reparos de veículos, reciclagem de eletrônicos etc.) vendidas ao governo comum rendimento de 583 milhões de dólares. Apesar dos subsídios financeiros, um mercado para a produção de detentos (dois terços das vendas são para o Departamento de Defesa) e salários médios míseros, entre 23 centavos a 1,15 dólar por hora, o programa gerou umfluxo de caixa negativo de US\$ 5 milhões (Federal Bureau of Prisons. UNICOR 2001 Annual Report. Disponível em 〈http://www.unicor.gov/ information/publications/pdfs/corporate/CATAR2ool.pdf〉, acessado em 11/o8/2007).

[22] Goldberg e Evans, op. cit., p. 1998.

\footnotetext{
[22] Zimring, Franklin E.e Hawkins, Gordon J. The scale of imprisonment. Chicago: University of Chicago Press, 1991, p. 173.
} 
[24] Feeley, Malcolm e Rubin, Edward L. Judicial policy making and the Modern State: How the courts reformed America's prisons. New York: Cornell University Press, 1998.

25] Glaser, Jordan B. e Greifinger, Robert B. "Correctional health care: a public health opportunity". Annals of Internal Medicine, vol. 118, $\mathrm{n}^{\mathrm{Q}}$ 2, 1993 , pp.139-145. N.T.
Recebido para publicação

em 25 de novembro de 2007.

\section{NOVOS ESTUDOS}

CEBRAP

80 , março 2008

pp. 9-19 finamento, e avigilância cada vez maior dos erros judiciais ${ }^{24}$. Assim, os juízes exigiram que as autoridades das cadeias e prisões cumprissem uma bateria de normas mínimas referentes a direitos individuais e serviços institucionais, o que significou, por exemplo, oferecer educação para presos menores de idade e atendimento psiquiátrico em massa. Mesmo que ainda deficiente, o sistema de saúde das prisões melhorou consideravelmente, a ponto de ser superior aos serviços médicos deficientes acessíveis aos condenados mais pobres do lado de fora, $e$ atende a milhões anualmente, tanto que pesquisadores da saúde pública e oficiais governamentais consideraram o sistema carcerário um ponto de intervenção crucial para diagnosticar e tratar uma série de doenças infecciosas comuns em populações de baixa renda ${ }^{25}$.

\section{CODA}

Escapar do paradigma angelical da imposição do cumprimento da lei e exorcizar o mito demoníaco do "complexo industrial prisional" são duas etapas necessárias e complementares para localizar de forma apropriada as novas funções que a prisão carrega no sistema reconfigurado de instrumentos para geriro trabalho não-regulamentado, a hierarquia etnorracial e a marginalidade urbana nos Estados Unidos dos dias de hoje. Realizar essas duas etapas revela que a liberação de um aparato penal hipertrófico e hiperativo após meados da década de 1970 não é a lâmina cega de uma "guerra contra o crime", nem o engendramento de um acordo secreto demoníaco entre oficiais públicos e corporações privadas com vistas a faturar com o encarceramento. Em vez disso, revela que o fenômeno participa da construção de um Estado reformado capaz de impor requerimentos econômicos e morais adstringentes do neoliberalismo após o descarte do pacto social fordista-keynesiano e a implosão do gueto negro. $\mathrm{O}$ aparecimento dessa nova administração da pobreza de mãos dadas com o workfare restritivo e com punições expansivas exige que tiremos a prisão dos domínios técnicos da criminologia e da política criminal, e a coloquemos diretamente no centro da sociologia política e das ações civis.

LOÏC WACQUANT é professor de sociologia na Universidade da Califórnia, em Berkeley, e pesquisador do Centre de Sociologie Européenne, Paris. Publicou recentemente no Brasil os livros OMistério do ministério: Pierre Bourdieu e a política democrática (Revan, 2005) e Onda punitiva: o novo governo da insegurança social (Revan, 2007). 